\title{
Accommodating bicycle and pedestrian traffic in sub-urban areas Sri Lanka
}

\author{
Chamali Hewawasam *1, Shamain Saparamadu ${ }^{2}$, Udya Abesinghe ${ }^{3}$, Mahanama, P.K.S. ${ }^{1}$ \\ ${ }^{1}$ Department of Town and Country Planning, University of Moratuwa, Katubedda, Sri Lanka \\ ${ }^{2}$ Department of Mathematics, University of Moratuwa \\ ${ }^{3}$ Department of Civil Engineering, University of Moratuwa
}

\begin{abstract}
The concept of sustainability has become a key idea in national and international discussion following the publication of Brundtland Commission Report. Sustainability in non-renewable resource management ultimately results in more energy saving options. However, it is less evident in a small scale and in energy saving terms. This paper attempts to highlight the importance of sustainable transportation for achieving the goal of promotion of energy saving cities. Objectives of the study are to identify a suitable road network to designate as bicycle and pedestrian priority roads and to identify modifications required to accommodate these non-motorized transport modes in promotion of sustainable transportation. A case study carried out in Rathmalana West area where roads were rehabilitated after a storm water drainage. Logical analysis to the collected information derived a suitable pedestrian/bicycle priority network that connects coastline to main arterial. The results rectified the provisions for increase public transport coverage and thereby concentrate on encouraging pedestrians and cyclists.
\end{abstract}

Keywords: Public transport, Road infrastructure, Sustainability, Sustainable transportation

\section{Introduction}

The concept of sustainability has become a key idea in national and international discussion following the publication of Brundtland Report. It was given further prominence in the context of the 2002 world summit on sustainable development held in Johannesburg. Sustainability ultimately results in more energy saving options. However it is less obviously applicable on a small scale and in energy saving terms. This paper attempts to highlight the importance of sustainable transportation for achieving the goal of promotion of energy saving cities. The objectives of the study are identify suitable road network to designate as bicycle and pedestrian priority roads and identify modifications required to accommodate these non-motorized transport modes in promotion of sustainable transportation.

Energy efficiency is one aspect of sustainable development which can be empowered by sustainable transportation. Energy efficiency may be the cheapest, most abundant, and most underutilized resource for local economic and community development. Generally, energy efficiency is using less energy in providing the same service. Efficient energy use, sometimes simply called energy efficiency, is the goal to reduce the amount of energy required to provide products and services. There are many

\footnotetext{
Corresponding author

(D) https://orcid.org/0000-0003-4593-4555

Email address: chamalihewawaam@uom.lk:. mahanama pks@yahoo.com

Received 11 August 2018; Received in revised form 21 March 2019; Accepted 8 June 2019

DOI: http://doi.org/10.4038/bhumi.v7i1.37
} 
motivations to improve energy efficiency such as reducing energy use. According to the International Energy Agency, improved energy efficiency in buildings, industrial processes and transportation could reduce the world's energy needs in 2050 by one third, and help control global emissions of greenhouse gases. In today's context motorized transportation is highly being used, which resulted in more energy waste and pollution. Walking and cycling receives a considerable interest as nonpolluting transportation mode which results in energy saving as opposed to motorized traffic. We can have more energy saving cities by reducing the motor traffic and promoting more pedestrian/cyclist friendly cities along with provision of public transport for daily travelling.

Rapid urbanization in recent decades has led to ever-expanding cities, creating massive requirements for energy to fuel growth and expand basic service infrastructure (Jayasinghe et al, 2019). This demand for energy has enormous implications for cities, particularly their operating budgets, competitiveness, service quality and cost, quality of life and local and global environmental impacts. Energy is widely viewed as the lifeblood of cities, powering public services, hospitals and schools while moving people within the city and beyond. Reducing energy use through energy efficiency measures and planning can lower a city's dependence on imported fuels and its energy costs while freeing up resources that can improve or extend city services. Improving a city's design and planning functions can have dramatic implications on future energy needs. Walking and cycling receive a considerable interest as non-polluting transportation mode which results in energy saving as opposed to motorized traffic. We can have more energy saving cities by reducing the motor traffic and promoting more pedestrian friendly cities.

The objectives of the study are identify suitable road network to designate as bicycle and pedestrian priority roads and identify modifications required to accommodate these non-motorized transport modes in promotion of sustainable transportation which intern resulting having sustainable energy efficient cities.

\section{Literature Review}

\subsection{Sustainability}

The principles of sustainability can be applied to cities though the guidance on how this can be done was not very clear in Agenda 21 or other United Nations documents (Keating, 1993). Anders (1991), in a global review of the sustainable cities movement, pointed out:

"The sustainable cities movement seems united in its perception that the state of the environment demands action and that cities are an appropriate forum in which to act' (p. 17). Others such as Yanarella and Levine (1992) suggest that all sustainability initiatives should be centered on strategies for designing, redesigning and building sustainable cities. From a global perspective, they suggest that cities shape the world and that we will never begin to implement the sustainability process unless we can relate it to cities.

The concept of sustainability has become a key idea in national and international discussions following the publication of the Brundtland Report and the 1992 Rio 'Earth Summit'. It was given further prominence in the context of the 2002 World Summit on Sustainable Development held in Johannesburg. Sustainable development is certainly a desirable and, more debatably, an attainable objective in global terms. However, it is less obviously applicable on a smaller scale, where it is sometimes used synonymously with concepts such as urban autonomy, selfreliance, or self-sufficiency.

While there appears to be general agreement on the need for planning for sustainable urban development, there is much less agreement on how this should be undertaken. Camagni (2002) describes how a 'wisely compact' settlement with several centers offering a wide range of services, for example, may create the 
most sustainable urban form. If appropriately planned, it has been argued that urban settlements can achieve an efficient use of space and resources unattainable by a scattered rural population. High population densities offer opportunities for efficient use of resources, such as electricity and transport facilities, as well as providing an efficient structure for waste disposal and sewage infrastructure (Giradet, 1999).

\subsection{Sustainable Transport}

There is no universally accepted definition of sustainability, sustainable development or sustainable transport. The term sustainable transportation came up with the expansion of sustainable development and there are many definitions for sustainable transport and of the related terms sustainable transportation or sustainable mobility. As per the European Union Council of ministers, sustainable transportation system is " one in which fuel consumption, vehicle emission, safety, congestion, and social and economic access are of such levels that they can be sustained into the indefinite future without causing great or irreparable harm to future generation of people throughout the world" The World Business Council for Sustainable Development defines sustainable mobility as "the ability to meet society's desires and needs to move freely, gain access, communicate, trade and establish relationships without sacrificing other essential human or ecological values, today or in the future." Although there are certainly many other useful definitions for sustainable transportation, this one expounds on the oftencited 1987 definition from the United Nations by naming specific needs and referring explicitly to mobility in transportation.

Transportation systems have significant impacts on the environment, accounting for $20 \%$ to $25 \%$ of world energy consumption and carbon dioxide emissions. Greenhouse gas emissions from transportation are increasing at a faster rate than in any other energy-using sector. Road transportation is also a major contributor to local air pollution and smog. Traditional transportation planning aims to improve mobility, especially for motor vehicles, and may fail to adequately consider wider impacts. However, attention should be given to access - to work, education, goods and services, and friends and family — and there are proven techniques to improve access while simultaneously reducing environmental and social impacts and managing traffic congestion. Such strategies include transit improvements, ridesharing, pedestrian and cycling improvements, delivery services, telecommuting, and location-efficient development. Communities that are successfully improving the sustainability of their transportation networks are doing so as part of a wider program to create more vibrant, safe, liveable, sustainable cities (Ratnayake, 2016); (Perera, 2018).

A true sustainable transportation network is partially created from a system that addresses multiple modalities, land use, and land use policy that is supportive of those modalities, for example, Transit-oriented development (Senevirathna \& De Silva, 2018). At the same time, maintaining the ease of use of the transportation system and expected travel times is critical for the improvement of and contentment with a transportation system. In other words, if people do not likethe alternatives they are provided, they will not use them; if people perceive changes to the automobile-oriented system as unfair, they will vote politicians out of office. As such, it is crucial that transportation planning not only promote sustainability but also utilize the traditional technical tools available in order to ensure a system that meets desired goals and is also liked and well utilized.

\section{Methods \& Materials}

The concept of sustainable transportation is less obviously applicable on a small scale sub urban context and in this study it attempts to identify ways and means of how to improve sustainable transportation option in a suburban area. This 
paper further, attempts to highlight the importance of sustainable transportation for achieving the goal of promotion of energy saving cities with the promotion of environmental friendly modes of transportation.

\subsection{Case study}

A case study carried out in Rathmalana West area where roads were rehabilitated after a storm water drainage project. With the rapid growth of suburban environment and higher percentage of low income and middle-income groups this area was ideal to examine the potentials for improving sustainable transportation modes, especially cycling and walking. Figure 1 shows the case study area with major land uses in the area.

\subsection{Data collection}

Data gather about information on road infrastructure, condition and usage in the case study area after a discussion. At the preliminary stage it was discussed that wider public transport coverage, easy and improved accessibility to public transport and encouraging environmental friendly modes of transportation such as walking and cycling will result in more sustainability at sub urban areas. A questionnaire survey was also carried out within the case study area interviewing residents and road users at random.
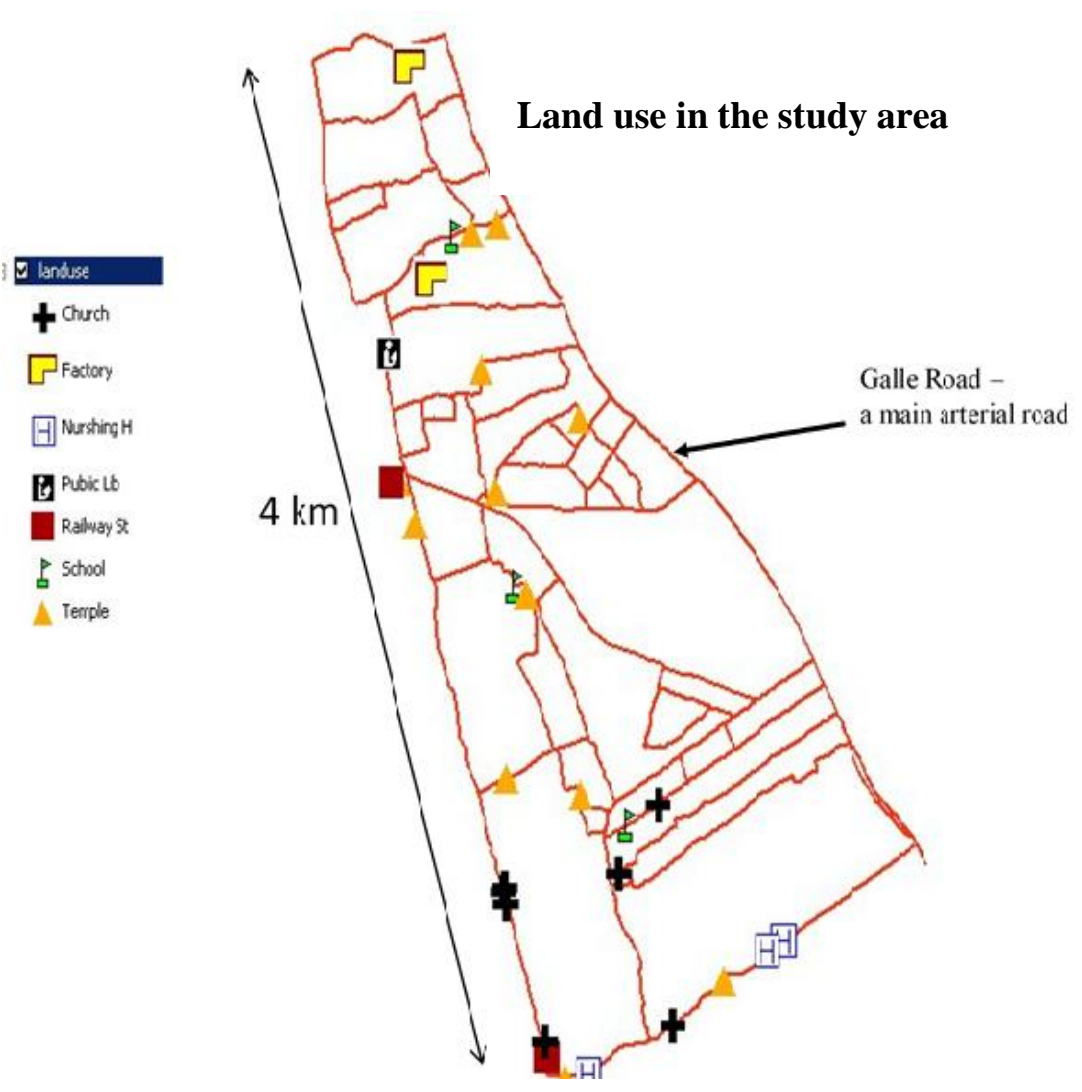

Figure 1: Case study area with its major land uses 
In the questionnaire different aspects were considered such as the use of road, assessment of current road infrastructure, safety of road and the additional elements to be included for a more pedestrian and cyclist friendly environment along with the users' perception for sustainable or environmental friendly transportation modes in the sub urban area.

\section{Analysis and Results}

The details about area was analysed at first and Table 1 indicates the vehicle mix at the study area.

Table 1: Vehicle mix in case study area

\begin{tabular}{|l|c|}
\hline \multicolumn{1}{|c|}{ Vehicle Type } & Percentage \\
\hline Bicycle & $37 \%$ \\
\hline $\begin{array}{l}\text { Three wheelers/Motor } \\
\text { Bicycle }\end{array}$ & $33 \%$ \\
\hline Car & $23 \%$ \\
\hline Bus/Truck & $7 \%$ \\
\hline
\end{tabular}

From the questionnaire survey the concerns identified such as safety due to poor road conditions and narrowness in residential area,

fast moving motorized traffic on road, safety at night, having to share the major arterial with motorized traffic, etc. The existing road widths are given in Figure 2.

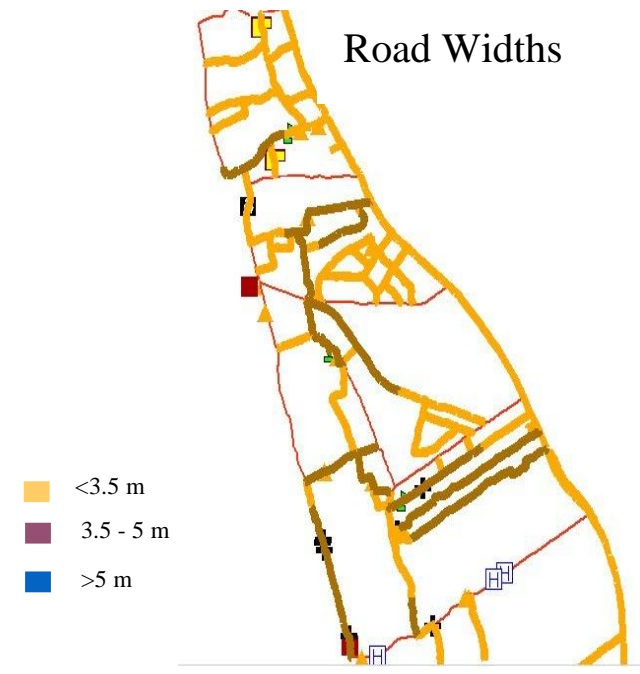

Figure 2: Existing road widths
Those collected information analysed to logically arrive at a suitable pedestrian/bicycle priority network that connect coastline to main arterial. After a detailed analysis of the area, it identified the provisions for increase public transport coverage and thereby concentrates on encouraging pedestrians and cyclists is the most viable and satisfactory action to improve sustainable transportation in the sub urban area.

Arc GIS tool utilize for spatial analysis of the area and to identify road inks to be upgraded. In this research, pedestrian demand links and nodes within the area are identifying using a network flow approach. The goal of the network flow approach is to identify and prioritize road links to be upgraded in the achievement of environmental friendly or improved sustainability in the sub urban area. The process was shown in figures as follows. (Figure 3 to 8 )
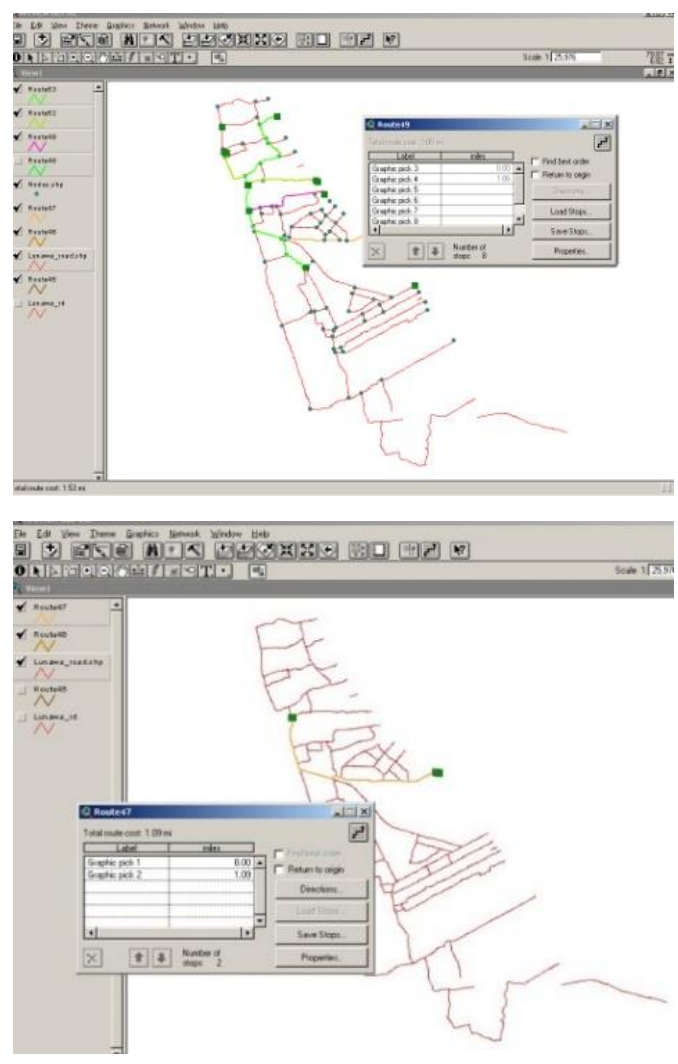

Figure 3: Develop Minimum Path Networks 
Minimum path networks for pedestrians and bicycles identified as shown in Figure $4 \& 5$

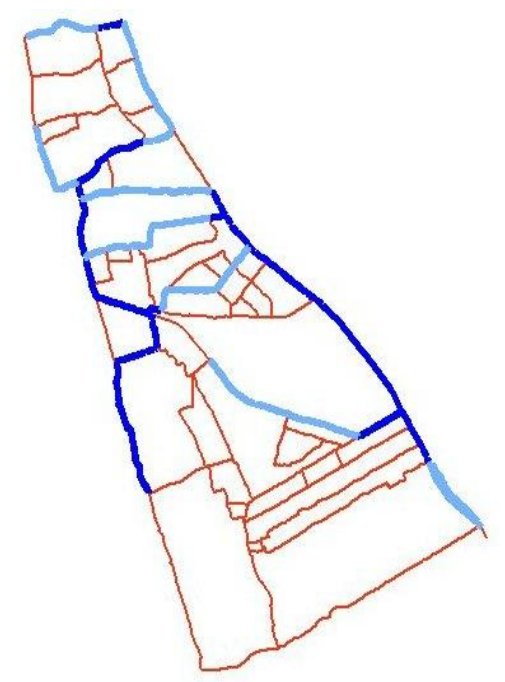

Figure 4: Minimum path network for pedestrians

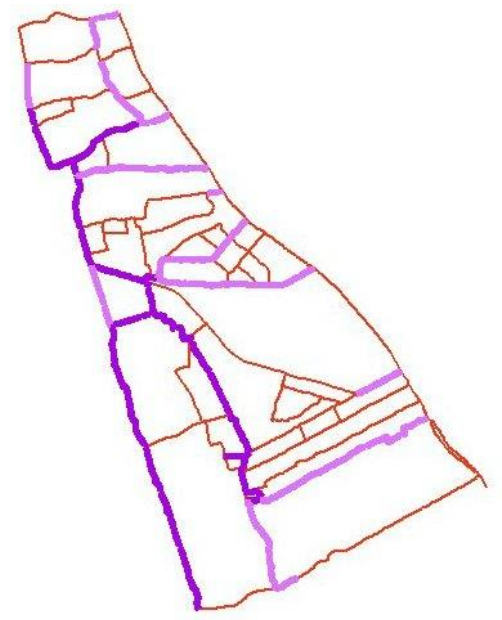

Figure 5: Minimum path network for bicycle

In both pedestrian and bicycle networks at least seven o-d pairs are connected through selected links. final identified minimum span tree is shown in figure 6.

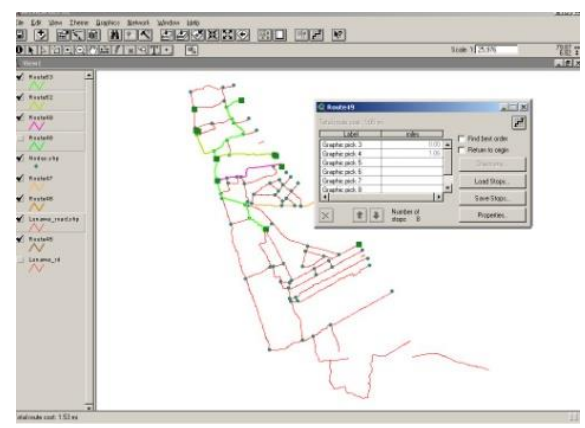

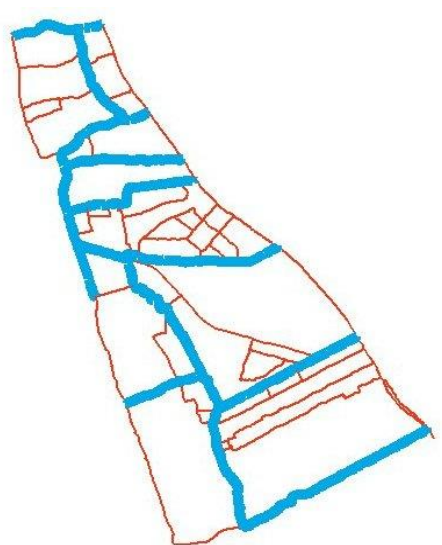

Figure 6: Identified minimum spanning tree Then higher usage of pedestrian and bicycle flows identified as shown in Figure 7.

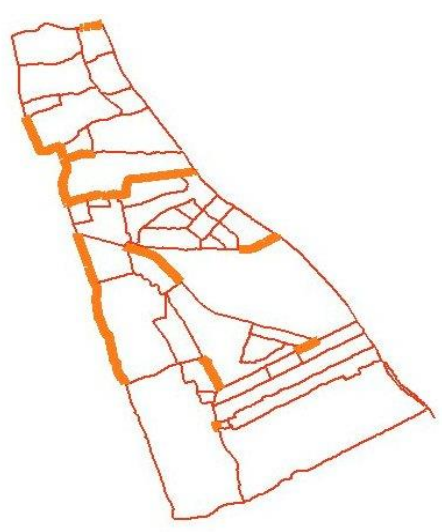

Figure 7: Links with higher usage for both pedestrians and cyclists

By a further analysis of all considerations namely, higher pedestrian and bicycle flow, minimum paths for pedestrians and bicycles, minimum spanning tree for al road inks for all road links the road links that needed improvements were identified. (Figure 8)

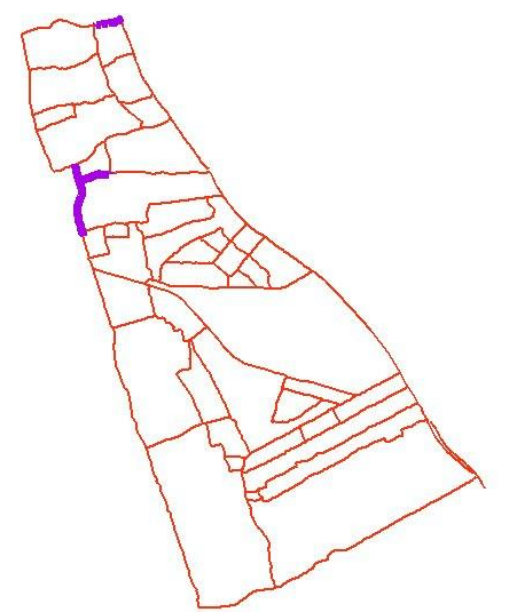

Figure 8: Road links that need improvements 


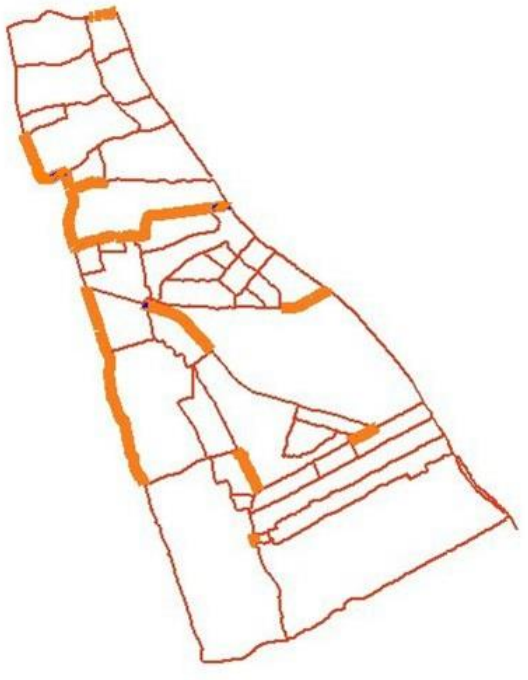

Figure 9: Links need to upgrade

Then another detail analysis of the area carried out to identify the provisions for increase public transport coverage thereby further provision of walking and cycling. The resulting map with inks to be upgraded is given in Figure 9

\section{Conclusion and Discussion}

During this study it identified that in order to promote walking and cycling it is a pre requisite to provide a higher coverage of public transport. A suitable road network to designate as bicycle and pedestrian priority road links was also identified as a means of promotion of waking and cycling. The results show the possibilities of achieving sustainability in sub urban areas of Sri Lanka and thereby achieve the goal of promotion of energy saving cities.

This study only focuses on walking and cycling as sustainable transport modes. Further research can carry out on all sustainable transport modes. We regard this as an ice breaker in the field and we anticipate that these results will be useful for transportation engineers, planners, and other professionals to make effective decisions in designing pedestrian infrastructure.

\section{Acknowledgement}

The authors acknowledge support of the Civil Engineering students for the data collection and survey works. We appreciate the cooperation received from the staff of the Department of Civil Engineering, University of Moratuwa.

\section{References}

Anders, R., 1991. The sustainable cities movement. Working paper no. 2, Institute for Resources and Security Studies, Cambridge, MA, USA

Camagni, R., (2002). On the concept of territorial competitiveness: sound or misleading? Urban Studies 39 (13), 2395-2411

Giradet, H. (1999) Creating sustainable cities. Devon: Green Book

Jayasinghe, A., Sano, K., Abenayake, C.C. and Mahanama, P.K.S., 2019. A novel approach to model traffic on road segments of large-scale urban road networks. MethodsX, 6, pp.1147-1163.

Perera, E.D.J., 2018. Co-evolutionary design concept for urban sustainability based on 'Regenerative' design principles: a case study in Salford, United Kingdom. Bhumi, The Planning Research Journal, 6(2), pp.29-37

Ratnayake, R. (2016). Fear of crime in urban settings: Influence of environmental features, presence of people and social variables. Bhumi: The Planning Research Journal, 3(2), 30-43. 
Senevirathne, S.W.M.P. and De Silva, P.C.P., 2018. A model to evaluate energy efficient spatial structure for transportation via spatially balancing the job - house ratio - The case of Sri Lanka. Bhumi, The Planning Research Journal, 6(2), pp.38-48.

Viteikiene, M. \& Zavadskas, E.K. (2007) Evaluating the sustainability of vilnius city residential areas, Journal of Civil Engineering and Management, 13:2, 149-155

Yanarella, E. J., and Levine, R.S. (1992) "Does sustainable development lead to sustainability?" Futures 24.8 759-774. 